\title{
The effects of $Y$ chromosome microdeletions on in vitro fertilization outcomes, health abnormalities in offspring and recurrent pregnancy loss
}

\author{
Andrew P. Golin", Wallace Yuen", Ryan Flannigan \\ Department of Urologic Sciences, University of British Columbia, Vancouver, BC, Canada \\ Contributions: (I) Conception and design: All authors; (II) Administrative support: None; (III) Provision of study materials or patients: None; (IV) \\ Collection and assembly of data: W Yuen, AP Golin; (V) Data analysis and interpretation: R Flannigan; (VI) Manuscript writing: All authors; (VII) \\ Final approval of manuscript: All authors. \\ \#These authors contributed equally to this work. \\ Correspondence to: Ryan Flannigan. Department of Urologic Sciences, University of British Columbia, Vancouver, BC, Canada. \\ Email: ryan.flannigan@ubc.ca.
}

\begin{abstract}
Male factor infertility accounts for approximately 50\% of all infertility evaluations. A common cause of severe oligozoospermia and azoospermia is Y chromosome microdeletions (YCMs). Men with these genetic microdeletions must typically undergo assisted reproductive technology (ART) procedures to obtain paternity. In this review, we performed a thorough and extensive search of the literature to summarize the effects of YCMs on in vitro fertilization (IVF) outcomes, health abnormalities in offspring and recurrent pregnancy loss (RPL). The PubMed database was searched using specific search terms and papers were identified using Preferred Reporting Items for Systematic Reviews and Meta-Analyses (PRISMA) guidelines. Sperm retrieval amongst men with complete AZFa and/or AZFb deletions is extremely rare and thus data on ARTs is largely unavailable. In AZFc-deleted men undergoing assisted reproduction, the collective fertilization rate (FR) is $59.8 \%$, the clinical pregnancy rate is $28.6 \%$ and the live birth rate is $23.4 \%$. When successful, the YCM is always transmitted to the male offspring and the deletion size either remains unchanged or widens. YCMs generally result in decreased fertilization, clinical pregnancy and live birth rates compared to men with intact $\mathrm{Y}$ chromosomes during ART interventions. There is a minimal or absent association of YCMs with abnormalities in the offspring or RPL.
\end{abstract}

Keywords: Fertilization in vitro; intracytoplasmic sperm injections (ICSIs); offspring; recurrent early pregnancy loss; Y chromosome microdeletion (YCM)

Submitted Oct 28, 2019. Accepted for publication May 15, 2020.

doi: 10.21037/tau-19-672

View this article at: http://dx.doi.org/10.21037/tau-19-672

\section{Introduction}

The advent of assisted reproductive technologies (ARTs) has enabled many subfertile men to achieve paternity. A subset of these subfertile men have $\mathrm{Y}$ chromosome microdeletions (YCMs). YCM are small deletions that range between $0.8-7.7 \mathrm{Mb}$, making them undetectable in karyotypes (1). Primarily, these deletions occur within a region known as the azoospermic factor $(\mathrm{AZF})$ gene locus (2) and can involve complete, partial or combinatory deletions of the $\mathrm{AZFa}, \mathrm{AZFb}, \mathrm{AZFc}$ and $\mathrm{AZFd}$ regions (3). Depending on the extent of deletion, men present with varying degrees of severity in sperm counts and testis histology. For instance, complete absence of the AZFc locus leads to oligozoospermia or azoospermia, and histologically feature sertoli cell only (SCO) syndrome, maturation arrest (MA) or hypospermatogenesis (HS) (3). On the other end of the spectrum, partial deletions of AZFc (gr/ gr deletions) are more benign and presentations range from 


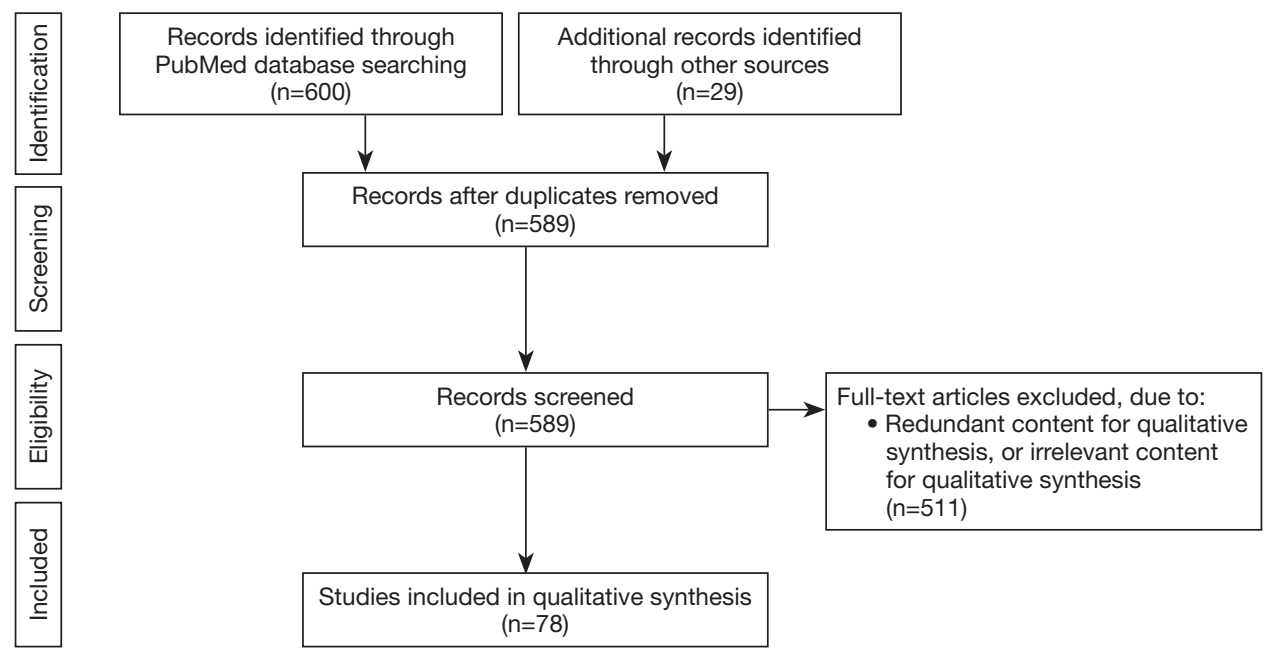

Figure 1 PRISMA flow diagram describing inclusion and exclusion process. From: Moher D, Liberati A, Tetzlaff J, et al. Preferred Reporting Items for Systematic Reviews and Meta-Analyses: the PRISMA statement. PLoS Med 2009;6:e1000097.

normozoospermia to azoospermia, with most histological biopsies showing MA (4,5). Additionally, flanking the YCM locus are the pseudoautosomal regions (PARs) that have been implicated in health abnormalities including stature differences and neuropsychiatric disorders $(6,7)$. Copy number variants $(\mathrm{CNVs})$ within PARs have been associated with terminal AZF deletions, and these are further reviewed (8). Evidently, YCM and alterations to nearby genetic regions can significantly impair spermatogenesis, cause male infertility and impact offspring health.

Men with cryptic or absent sperm counts who cannot conceive naturally often typically undergo surgical sperm retrieval, such as microdissection testicular sperm extraction (microTESE), and subsequent assisted fertilization techniques, such as in vitro fertilization (IVF) with intracytoplasmic sperm injection (ICSI), in order to conceive. MicroTESE is a surgical procedure involving general anesthesia, whereupon a urologist precisely extracts sperm from dilated seminiferous tubules under microscopic guidance (9).

Little information is known regarding the success rates of ART in large samples of men with YCM, and the effects of YCM on the health of offspring and on recurrent pregnancy loss (RPL). This review was performed to summarize the effects of YCM pertaining to IVF ICSI results, health of offspring and RPL.

\section{Material and methods}

Publications were identified using the PubMed search engine. Inclusion criteria included full text availability and English language studies published between January 1997-May 21, 2019 with the following search terms: "Y chromosome microdeletion", "fertilization", "offspring", "sperm retrieval", "therapy", "gr/gr", "AZFa”, "AZFb”, "AZFc", "microTESE”, "micro-TESE”, "microdissection testicular sperm extraction", "micro TESE”, “male infertility", and "hormone therapy". Six hundred publications were extracted, and upon duplication removal, a total of 560 articles remained. Twenty-nine articles after the initial search were added. All abstracts were read, and those containing pertinent information were included. A total of 78 papers are included in this review article. A diagram of the inclusion and exclusion processes are represented as a Preferred Reporting Items for Systematic Reviews and Meta-Analyses (PRISMA) in Figure 1.

\section{Y chromosome microdeletions}

Male factor infertility accounts for approximately $50 \%$ of all couples seeking infertility assessments. The prevalence of YCM among oligozoospermic or azoospermic infertile men vary depending on ethnicity and geographic region, but it is estimated to be approximately $7.6 \%$ (10). Clinically significant microdeletions of the $\mathrm{Y}$ chromosome involved with spermatogenesis are typically located in the long arm (Yq) of the chromosome, which contains the AZF locus. The AZF locus has been genetically mapped and is separated into four genetic loci (AZFa, $\mathrm{AZFb}, \mathrm{AZFc}$, 
AZFd). The severity of impaired spermatogenesis is greatest in deletions closer to the centromere (AZFa followed by $\mathrm{AZFb}$, then $\mathrm{AZF}$ ), with $\mathrm{AZFd}$ being clinically insignificant. In addition to the specific locus deleted, the size of the deletion is significant for prognosis, with multiple deletions being more detrimental to sperm counts than single deletions. Some men with YCMs will have rare sperm in their ejaculate, while others will require surgical sperm retrieval from the testis. In the presence of sperm, nearly all men with YCMs will require IVF with ICSI due to limited number of sperm to maximize their odds of paternity.

In general, beside AZFc deletions, other complete deletion types result in severe impairment of spermatogenesis and thus, poor or non-existent sperm retrieval rates (SRRs). Given this, sperm retrieval techniques are often not offered for men with AZFa and/or $\mathrm{AZFb}$ deletions. As a result, ART data is widely unavailable for these men. In the literature, men with $\mathrm{AZFa}$ and/or $\mathrm{AZFb}$ deletions who undergo successful sperm retrieval and subsequent ART typically have partial deletions. However, a case report published in 2016 (11) reported a severely oligoasthenozoospermic man with a complete $\mathrm{AZFb}$ deletion who underwent ICSI which resulted in the delivery of a healthy boy, who obtained the same deletion as his father. Although limited, studies including male participants with complete AZFa and/or AZFb YCM are included in [http://cdn.amegroups.cn/static/application/d4e5346eea8c 05fb1f5182fa0e59c07b/tau-19-672-1.pdf; year 1998-2010: (12-30); year 2010-2018 (31-44)] of this review.

\section{IVF outcomes}

The advent of IVF, and ICSI, has enabled infertile men with YCM to have their own offspring. Depending on the type and size of YCM, ICSI success varies. Pertinent studies with sufficient information on ICSI success are included in [http://cdn.amegroups.cn/static/application/d4e5346eea8c 05fb1f5182fa0e59c07b/tau-19-672-1.pdf; year 1998-2010: (12-30); year 2010-2018 (31-44)]. Because any YCM besides AZFc-deletions failed with sperm retrieval, success rates are only calculated in AZFc-deleted men.

The SRR, fertilization, clinical pregnancy and live birth rates were totaled from 34 studies, between 1998 and 2018, categorized based on the type of YCM and resulting phenotype (ranging from azoospermia to oligozoospermia) [http://cdn.amegroups.cn/static/application/d4e5346eea 8c05fb1f5182fa0e59c07b/tau-19-672-1.pdf; year 1998-
2010: (12-30); year 2010-2018 (31-44)]. Furthermore, we present the number of embryo transfers, cleaved embryo rate and birth defect rate for the studies that provided the data. Those studies that listed a percentage without the corresponding frequency were omitted (i.e., $60 \% \mathrm{vs}$. $6 / 10)$ due to inability to sum the values. The reviewed studies spanned different time periods and used different sequencing technologies to define the YCM types; thus, we defined "Men with YCM" as men who had an incomplete or complete deletion in the AZF loci (AZFa, AZFb, AZFc). "Men without YCM" were defined as sub-fertile or infertile men who had no detectable YCM but underwent ART and were used as the comparative group in the calculated data. Men without any YCM had a fertilization, clinical pregnancy, and live birth rate of $69.8 \%(3,940 / 5,645)$, $42.2 \%(265 / 628)$, and $43.2 \%$ (134/310) respectively. Men with any deletion had a fertilization, clinical pregnancy, and live birth rate of $61.8 \%(5,440 / 8,801), 30.4 \%(249 / 818)$ and 25.4\% (223/879), respectively.

The fertilization rate (FR) for men with any deletion type when sperm was testicular-derived (mTESE) or ejaculatederived were $38.6 \%(73 / 189)$ and $60.5 \%(1,389 / 2,297)$, respectively. For men with or without a deletion, the FR from testicular origin was $45.9 \%(177 / 386)$ and from ejaculate origin was $63.5 \%(2,723 / 4,287)$. Although the heterogeneity and other potentially confounding factors of the studies were not considered, it appears that the FR is higher amongst men whose sperm is from the ejaculate.

Unlike the FR, the clinical pregnancy and live birth rates show opposite trends. The clinical pregnancy rates amongst men with any deletion type were $38.5 \%(10 / 26)$ and $31.4 \%$ (54/172) for testicular and ejaculate-derived sperm, respectively. For all men (with or without a deletion), the rates were $48.7 \%(19 / 39)$ and $32.1 \%$ (108/336) for testicular and ejaculate-derived sperm, respectively. Analogous to clinical pregnancy trends, the live birth rates are higher amongst testicular-derived sperm. The live birth rates for AZF-deleted men are $42.9 \%(9 / 21)$ and $25.3 \%(43 / 170)$ for testicular and ejaculate-derived sperm. There were no men without an AZF deletion that underwent mTESE, so the live birth rate is the same for men with or without an AZF deletion. However, for men with or without a deletion whose sperm was obtained from the ejaculate, the live birth rate was almost identical $(25.4 \%, 73 / 287)$ in these studies.

Though it has not been directly investigated in men with YCM, there are studies that suggest there may be a role for testicular sperm retrieval for ART in cryptozoospermic men who have prior unsuccessful IVF 
processes with ejaculated sperm. In a systematic review and meta-analysis by Kang et al. (45), testicular sperm lead to higher good-quality embryo rate, implantation rate and pregnancy rate when compared to ejaculated sperm. Similarly, Ketabchi (46), in a prospective cohort study, also found that TESE or percutaneous epidydimal sperm aspiration produced significantly better outcomes compared to ejaculated sperm. These results suggest testicular sperm may be superior to ejaculated sperm when it comes to ART; however, other confounding variables in these studies such as elevated DNA fragmentation and recurrent failure of IVF cycles may contribute to these findings. However, Abhyankar et al. (47) conducted a meta-analysis with five cohort studies that suggests there is no difference in pregnancy rates or FRs between using testicular and ejaculated sperm for ICSI in cryptozoospermic men. One of the cohort studies included in the meta-analysis involved retrospectively examining cryptozoospermic men who first had ART with ejaculated sperm then ART with testicular sperm (48). In this study, testicular sperm compared to ejaculate resulted in higher pregnancy and implantation rates. It appears for cryptozoospermic men, despite some conflicting results, there may be a role for testicular sperm retrieval for ART if IVF with ejaculated sperm fails. In azoospermic men, this is less relevant because azoospermic men are less likely to have ejaculated sperm for IVF. In conclusion, testicular sperm retrieval for ART in cryptozoospermic men who have prior unsuccessful IVF processes with ejaculated sperm may be applicable for severely oligozoospermic men with YCM, though further research examining this approach in this specific population is necessary before conclusions can be reached.

The AZFc deletion subtype has the highest SRR. Given this, men with AZFc deletions have had the most opportunities of attempting ICSI. Of the studies in [http:// cdn.amegroups.cn/static/application/d4e 5346eea8c05fb1f5 182fa0e59c07b/tau-19-672-1.pdf; year 1998-2010: (12-30); year 2010-2018 (31-44)] that had data on clinical pregnancy and live births amongst AZFc-deleted men, the clinical pregnancy and live birth rates were 28.6\% (167/584) and $23.4 \%$ (94/402), respectively. The United States CDC reports that in fresh embryos from fresh nondonor eggs, the percentage of transfers resulting in pregnancies ranged from $52.9 \%$ (age <35) to $15.2 \%$ (age >42) and the percentage of transfers resulting in live births ranged from $45.7 \%$ (age $<35$ ) to $7.8 \%$ (age $>42$ ) (49). Similarly, the clinical pregnancy and live birth rates for non-AZF deleted men from the studies in [http://cdn.amegroups.cn/static/ application/d4e $5346 \mathrm{eea} 8 \mathrm{c} 05 \mathrm{fb} 1 \mathrm{f} 5182 \mathrm{fa} 0 \mathrm{e} 59 \mathrm{c} 07 \mathrm{~b} / \mathrm{tau}-$ 19-672-1.pdf; year 1998-2010: (12-30); year 2010-2018 (31-44)] were $42.2 \%(265 / 628)$ and $43.2 \%(134 / 310)$, respectively. These data did include studies that reported both clinical pregnancy and live birth rate, and live birth rates or clinical pregnancy rates. The clinical pregnancy and live birth rates in AZFc-deleted men are lower than the controls in [http://cdn.amegroups.cn/static/application/d4 e5346eea8c05fb1f5182fa0e59c07b/tau-19-672-1.pdf; year 1998-2010: (12-30); year 2010-2018 (31-44)]. Although the data are minimal, studies have also shown lower quality embryo characteristics $(17,18,30)$. However, several studies have also shown that YCM in general do not negatively affect embryo characteristics $(20,21,23,33,36,37,39,50)$. With the heterogeneity contained in the data reviewed here, a meta-analysis would provide benefit. Furthermore, a prospective multi-center study would importantly contribute to accurately determine whether fertilization, clinical pregnancy and live birth rates are lower in AZFcdeleted men compared to AZF-intact men.

\section{Vertical transmission of YCM}

Infertile men with YCM will transmit the YCM to their male offspring $(15,18,27,51-54)$. Therefore, couples attempting ICSI to circumvent male factor infertility are regularly counselled regarding the transmission of YCM to their sons and consequently, the transmission of impaired reproductive fitness. Although the vertical transmission of Yq deletions are generally expected, the transmission of the identical fertility phenotype is not always present $(16,55,56)$. Chang et al. reports a fertile father of four infertile sons, who all have the same deletion as the father. This is likely due to an increase of the size of the deletion among the offspring (16). At the time of that study, the exact molecular extensions of the deletions could not be distinguished by interval mapping. Another report describes a similar case where an infertile son gained a YCM from his fertile father via natural conception (57). In this case however, the YCM increased in size, which explained the difference in phenotypes. There is conflicting data in the literature regarding the size of transmitted YCM in the offspring. Data in some studies suggest YCM remain the same size $(16,18,58)$, whereas other studies report enlarged deletions among offspring $(57,58)$. Therefore, the data suggests that either identical or enlarged deletions are passed onto the progeny. To circumvent transmission of YCM into 
offspring, it is also possible for couples attempting IVF in certain countries to employ preimplantation genetic diagnosis (PGD). With this technique, genetic information can be obtained from fertilized eggs, allowing couples to select for female embryos and therefore avoid the risk of transferring YCM to male offspring. The ethics surrounding selection of genetic traits, such as sex, however, is heavily debated.

With regards to increased frequency of de novo occurrence of YCM in offspring conceived via ICSI, the data is inconclusive (58-61). Some of these studies suggest an increased frequency of de novo YCMs occur because of ICSI, whereas other papers suggest no association is present. Due to the inconsistent data and the limited number of studies, we cannot confidently conclude whether an association between de novo YCM occurrence and ICSI is present.

\section{Health abnormalities}

New and improved ARTs have enabled infertile men with YCM to more easily have offspring. As a result, apart from the well-known transmission of AZF deletions and subsequently infertility to male offspring, it is critical for parents to understand whether other health abnormalities are more likely to occur in their children as a result of YCM.

The two flanks of the $\mathrm{Y}$ chromosome are PARs. While the function of the majority of PAR genes are unknown, haploinsufficiency of the short stature homeobox (SHOX) gene is associated with shortness and SHOX duplications are correlated with variable height (6). Jorgez et al. sought to determine whether men with YCM also have genetic defects in PARs (7). They proposed that the mechanisms causing YCM are associated with genetic aberrations outside the AZF regions, such as PARs. The men in this study with YCM and PAR CNVs were extremely short ( $<3{ }^{\text {rd }}$ percentile) or had drastically variable statures $\left(<25^{\text {th }}\right.$ percentile, $>95^{\text {th }}$ percentile), whereas the height of the men without PAR $\mathrm{CNV}$ s was around the $50^{\text {th }}$ percentile. Interestingly, all men with AZFbc deletions and abnormal karyotypes had PAR defects (7). Similarly, another study showed that CNVs in the PARs were solely present in participants with terminal AZFbc deletions (8). They did not identify any PAR CNVs in patients with interstitial $\mathrm{AZFa}, \mathrm{AZFb}, \mathrm{AZF}$, or $\mathrm{AZFbc}$ deletions. In addition to growth disorders, and as speculated by Jorgez et al., their results showed that patients with PAR $\mathrm{CNVs}$ were associated with neuropsychiatric disorders (8).
However, AZF deletions of Yq do not appear to negatively affect the intellectual, psychological or motor development of children (62).

Chromosomally abnormal embryos were observed in patients with YCM, with a significant percentage of embryos with monosomy X (30). Multiple authors have proposed an association between YCM and 45X/46XY due to the mitotic instability of the YCM (32,54,63-67). However, data have also shown that embryos from men with YCM are at no increased risk of negative characteristics $(20,21,23,33,36,37,39,50)$. It may be beneficial for future studies to investigate whether the type and size of YCM and other confounding variables have an effect on the association to better elucidate the relationship between YCM and health abnormalities.

\section{Recurrent pregnancy loss}

RPL is a heterogenous condition affecting $0.5-3 \%$ of couples $(68,69)$. It is typically defined as a loss of three or more consecutive pregnancies before the $28^{\text {th }}$ gestational week. Numerous aetiologies influence RPL, such as anatomical, endocrinological, hematological, immunological, environmental, and genetic factors (69). Despite numerous causes, approximately $50 \%$ of couples have no explanation for their RPL.

YCMs have been investigated to evaluate their association with RPL. Numerous studies have investigated the prevalence of YCM among men whose partner has experienced RPL, however, results were contradictory (70-78). Of the nine relevant papers, five studies state it is highly unlikely that an association exists between YCM and RPL $(72,73,75,76,78)$. Two of the four papers suggesting an association does exist have been argued against due to their patient selection criteria and methodology which did not conform to the European Academy of Andrology or the European Molecular Genetics Quality Network guidelines (78). In Li et al., they identified chromosomal abnormalities in men who experience RPL, and subsequently determined an association between chromosomal abnormalities and YCM (74). However, it was not established whether RPL was a result of the chromosomal abnormality or the YCM. Therefore, the directionality of the association is unclear. In Soleimanian et al., they suggested that there is an association between fertile men with specific incomplete AZFc loci deletions and RPLs; however the relatively small sample size $(\mathrm{n}=30)$ in an Iranian population weakens 
the power of their association (77). In summary, given that the majority of the screened studies argue against an association, and that several studies have reported no changes to embryo characteristics due to YCM, data would suggest no relationship exists between RPL and YCMs $(21,50)$.

\section{Conclusions}

In this review, the effects of YCMs on fertility outcomes were systematically reviewed and summarized. Sperm retrieval is not generally reported for men with complete $\mathrm{AZFa}$ and/or $\mathrm{AZFb}$ deletions, although exceptional cases have been reported, and thus the literature of ICSI results amongst these men is limited. For couples that attempt ICSI, we suggest there is a decreased fertilization, clinical pregnancy and live birth rates amongst men with YCM. Therefore, IVF results for men with AZFc deletions appear to be lower than men with intact $Y$ chromosomes. When a son is born, the deletion is consistently propagated and the size of the deletion either remains the same or enlarges. The phenotype of infertility, however, is typically passed on. Although the data is limited, the literature also suggests a minimal or absent association between YCM and health abnormalities in offspring and amid YCM and RPL.

\section{Acknowledgments}

Funding: None.

\section{Footnote}

Provenance and Peer Review: This article was commissioned by the Guest Editors (Keith Jarvi and Jared Bieniek) for the series "Genetic Causes and Management of Male Infertility" published in Translational Andrology and Urology. The article was sent for external peer review organized by the Guest Editors and the editorial office.

Conflicts of Interest: All authors have completed the ICMJE uniform disclosure form (available at http://dx. doi. org/10. 21037/tau-19-672). The series "Genetic Causes and Management of Male Infertility" was commissioned by the editorial office without any funding or sponsorship. RF reports grants from American Society of Reproductive Medicine, grants from Canadian Institute of Health Research, grants from Canadian Urologic Association
Scholarship Foundation, grants from New Frontiers Research Fund, grants from Vancouver Coastal Health Research Institute, personal fees from Paladin Labs, personal fees from Boston Scientific, outside the submitted work. The other authors have no other conflicts of interest to declare.

Ethical Statement: The authors are accountable for all aspects of the work in ensuring that questions related to the accuracy or integrity of any part of the work are appropriately investigated and resolved.

Open Access Statement: This is an Open Access article distributed in accordance with the Creative Commons Attribution-NonCommercial-NoDerivs 4.0 International License (CC BY-NC-ND 4.0), which permits the noncommercial replication and distribution of the article with the strict proviso that no changes or edits are made and the original work is properly cited (including links to both the formal publication through the relevant DOI and the license). See: https://creativecommons.org/licenses/by-nc-nd/4.0/.

\section{References}

1. Stahl PJ, Schlegel PN. Genetic evaluation of the azoospermic or severely oligozoospermic male. Curr Opin Obstet Gynecol 2012;24:221-8.

2. Kent-First $M$, Muallem A, Shultz J, et al. Defining regions of the Y-chromosome responsible for male infertility and identification of a fourth AZF region (AZFd) by Y-chromosome microdeletion detection. Mol Reprod Dev 1999;53:27-41.

3. Vogt PH. Human chromosome deletions in Yq11, AZF candidate genes and male infertility: history and update. Mol Hum Reprod 1998;4:739-44.

4. Shahid M, Dhillon VS, Khalil HS, et al. Associations of Y-chromosome subdeletion gr/gr with the prevalence of Y-chromosome haplogroups in infertile patients. Eur J Hum Genet 2011;19:23-9.

5. Stouffs K, Lissens W, Tournaye H, et al. What about gr/gr deletions and male infertility? Systematic review and metaanalysis. Hum Reprod Update 2011;17:197-209.

6. Thomas NS, Harvey JF, Bunyan DJ, et al. Clinical and molecular characterization of duplications encompassing the human SHOX gene reveal a variable effect on stature. Am J Med Genet Part A 2009;149A:1407-14.

7. Jorgez CJ, Weedin JW, Sahin A, et al. Aberrations in pseudoautosomal regions (PARs) found in infertile men 
with Y-chromosome microdeletions. J Clin Endocrinol Metab 2011;96:E674-9.

8. Castro A, Rodriguez F, Florez M, et al. Pseudoautosomal abnormalities in terminal $\mathrm{AZFb}+\mathrm{c}$ deletions are associated with isochromosomes $\mathrm{Yp}$ and may lead to abnormal growth and neuropsychiatric function. Hum Reprod 2017;32:465-75.

9. Flannigan R, Bach PV, Schlegel PN. Microdissection testicular sperm extraction. Transl Androl Urol 2017;6:745-52.

10. Colaco S, Modi D. Genetics of the human Y chromosome and its association with male infertility. Reprod Biol Endocrinol 2018;16:14.

11. Schwarzer JU, Steinfatt H, Schleyer M, et al. Microdissection TESE is superior to conventional TESE in patients with nonobstructive azoospermia caused by $\mathrm{Y}$ chromosome microdeletions. Andrologia 2016;48:402-5.

12. Silber SJ, Alagappan R, Brown LG, et al. Y chromosome deletions in azoospermic and severely oligozoospermic men undergoing intracytoplasmic sperm injection after testicular sperm extraction. Hum Reprod 1998;13:3332-7.

13. Rossato M, Ferlin A, Garolla A, et al. Case report: high fertilization rate in conventional in-vitro fertilization utilizing spermatozoa from an oligozoospermic subject presenting microdeletions of the $\mathrm{Y}$ chromosome long arm. Mol Hum Reprod 1998;4:473-6.

14. Kleiman SE, Yogev L, Gamzu R, et al. Three-generation evaluation of Y-chromosome microdeletion. J Androl 1999;20:394-8.

15. Page DC, Silber S, Brown LG. Men with infertility caused by AZFc deletion can produce sons by intracytoplasmic sperm injection, but are likely to transmit the deletion and infertility. Hum Reprod 1999;14:1722-6.

16. Chang PL, Sauer MV, Brown S. Y chromosome microdeletion in a father and his four infertile sons. Hum Reprod 1999;14:2689-94.

17. van Golde RJT, Wetzels AM, de Graaf R, et al. Decreased fertilization rate and embryo quality after ICSI in oligozoospermic men with microdeletions in the azoospermia factor $\mathrm{c}$ region of the $\mathrm{Y}$ chromosome. Hum Reprod 2001;16:289-92.

18. Oates RD, Silber S, Brown LG, et al. Clinical characterization of 42 oligospermic or azoospermic men with microdeletion of the AZFc region of the $\mathrm{Y}$ chromosome, and of 18 children conceived via ICSI. Hum Reprod 2002;17:2813-24.

19. Peterlin B, Kunej T, Sinkovec J, et al. Screening for $Y$ chromosome microdeletions in 226 Slovenian subfertile men. Hum Reprod 2002;17:17-24.

20. Kihaile PE, Kisanga RE, Aoki K, et al. Embryo outcome in Y-chromosome microdeleted infertile males after ICSI. Mol Reprod Dev 2004;68:176-81.

21. Choi JM, Chung P, Veeck L, et al. AZF microdeletions of the $\mathrm{Y}$ chromosome and in vitro fertilization outcome. Fertil Steril 2004;81:337-41.

22. de Llanos M, Ballescà JL, Gázquez C, et al. High frequency of gr/gr chromosome $\mathrm{Y}$ deletions in consecutive oligospermic ICSI candidates. Hum Reprod 2005;20:216-20.

23. Kihaile PE, Yasui A, Shuto Y. Prospective assessment of Y-chromosome microdeletions and reproductive outcomes among infertile couples of Japanese and African origin. J Exp Clin Assist Reprod 2005;2:9.

24. Stouffs K, Lissens W, Tournaye H, et al. The choice and outcome of the fertility treatment of 38 couples in whom the male partner has a Yq microdeletion. Hum Reprod 2005;20:1887-96.

25. Minor A, Wong EC, Harmer K, et al. Molecular and cytogenetic investigation of $\mathrm{Y}$ chromosome deletions over three generations facilitated by intracytoplasmic sperm injection. Prenat Diagn 2007;27:743-7.

26. Stahl PJ, Masson P, Mielnik A, et al. A decade of experience emphasizes that testing for $\mathrm{Y}$ microdeletions is essential in American men with azoospermia and severe oligozoospermia. Fertil Steril 2010;94:1753-6.

27. Plotton I, Ducros C, Pugeat M, et al. Transmissible microdeletion of the Y-chromosome encompassing two DAZ copies, four RBMY1 copies, and both PRY copies. Fertil Steril 2010;94:2770.e11-6.

28. Gambera L, Governini L, De Leo V, et al. Successful multiple pregnancy achieved after transfer of frozen embryos obtained via intracytoplasmic sperm injection with testicular sperm from an AZFc-deleted man. Fertil Steril 2010;94:2330.e1-3.

29. Kilic S, Yukse B, Tasdemir N, et al. Assisted reproductive treatment applications in men with normal phenotype but 45,X/46,Xy mosaic karyotype: clinical and genetic perspectives. Taiwan J Obstet Gynecol 2010;49:199-202.

30. Mateu E, Rodrigo L, Martínez MC, et al. Aneuploidies in embryos and spermatozoa from patients with $y$ chromosome microdeletions. Fertil Steril 2010;94:2874-7.

31. Shi YC, Cui YX, Zhou YC, et al. A rare Y chromosome constitutional rearrangement: A partial AZFb deletion and duplication within chromosome $\mathrm{Yp}$ in an infertile man with severe oligoasthenoteratozoospermia. Int J Androl 2011;34:461-9. 
32. Kim MJ, Choi HW, Park SY, et al. Molecular and cytogenetic studies of 101 infertile men with microdeletions of $\mathrm{Y}$ chromosome in 1,306 infertile Korean men. J Assist Reprod Genet 2012;29:539-46.

33. Liu XH, Qiao J, Li R, et al. Y chromosome AZFc microdeletion may not affect the outcomes of ICSI for infertile males with fresh ejaculated sperm. J Assist Reprod Genet 2013;30:813-9.

34. Choi DK, Gong IH, Hwang JH, et al. Detection of Y chromosome microdeletion is valuable in the treatment of patients with nonobstructive azoospermia and oligoasthenoteratozoospermia: sperm retrieval rate and birth rate. Korean J Urol 2013;54:111-6.

35. Sen S, Ambulkar P, Hinduja I, et al. Susceptibility of gr/ gr rearrangements to azoospermia or oligozoospermia is dependent on DAZ and CDY1 gene copy deletions. J Assist Reprod Genet 2015;32:1333-41.

36. Zhu YC, Wu TH, Li GG, et al. Decrease in fertilization and cleavage rates, but not in clinical outcomes for infertile men with AZF microdeletion of the $\mathrm{Y}$ chromosome. Zygote 2015;23:771-7.

37. Zhu Y, Wu T, Li G, et al. The sperm quality and clinical outcomes were not affected by sY152 deletion in $\mathrm{Y}$ chromosome for oligozoospermia or azoospermia men after ICSI treatment. Gene 2015;573:233-8.

38. Ko JK, Chai J, Lee VC, et al. Sperm retrieval rate and pregnancy rate in infertile couples undergoing in-vitro fertilisation and testicular sperm extraction for nonobstructive azoospermia in Hong Kong. Hong Kong Med J 2016;22:556-62.

39. Liu XY, Wang RX, Fu Y, et al. Outcomes of intracytoplasmic sperm injection in oligozoospermic men with $\mathrm{Y}$ chromosome $\mathrm{AZFb}$ or AZFc microdeletions. Andrologia 2017. doi: 10.1111/and.12602.

40. Goncalves C, Cunha M, Rocha E, et al. Y-chromosome microdeletions in nonobstructive azoospermia and severe oligozoospermia. Asian J Androl 2017;19:338-45.

41. Zhang YS, Li LL, Xue LT, et al. Complete azoospermia factor b deletion of Y chromosome in an infertile male with severe oligoasthenozoospermia: case report and literature review. Urology 2017;102:111-5.

42. Arafa MM, Majzoub A, AlSaid SS, et al. Chromosomal abnormalities in infertile men with azoospermia and severe oligozoospermia in Qatar and their association with sperm retrieval intracytoplasmic sperm injection outcomes. Arab
J Urol 2017;16:132-9.

43. Bahmanimehr A, Zeighami S, Namavar Jahromi B, et al. Detection of $\mathrm{Y}$ chromosome microdeletions and hormonal profile analysis of infertile men undergoing assisted reproductive technologies. Int J Fertil Steril 2018;12:173-7.

44. Sabbaghian M, Mohseni Meybodi A, Rafaee A, et al. Sperm retrieval rate and reproductive outcome of infertile men with azoospermia factor c deletion. Andrologia 2018;50:e13052.

45. Kang YN, Hsiao YW, Chen CY, et al. Testicular sperm is superior to ejaculated sperm for ICSI in cryptozoospermia: an update systematic review and meta-analysis. Sci Rep 2018;8:7874.

46. Ketabchi AA. Intracytoplasmic sperm injection outcomes with freshly ejaculated sperms and testicular or epididymal sperm extraction in patients with idiopathic cryptozoospermia. Nephrourol Mon 2016;8:e41375.

47. Abhyankar N, Kathrins M, Niederberger C. Use of testicular versus ejaculated sperm for intracytoplasmic sperm injection among men with cryptozoospermia: a meta-analysis. Fertil Steril 2016;105:1469-75.e1.

48. Ben-Ami I, Raziel A, Strassburger D, et al. Intracytoplasmic sperm injection outcome of ejaculated versus extracted testicular spermatozoa in cryptozoospermic men. Fertil Steril 2013;99:1867-71.

49. Centers for Disease Control and Prevention, American Society for Reproductive Medicine, Society for Assisted Reproductive Technology. 2016 Assisted Reproductive Technology Fertility Clinic Success Rates Report. Atlanta: US Dept of Health and Human Services, 2018.

50. Mulhall JP, Reijo R, Alagappan R, et al. Azoospermic men with deletion of the DAZ gene cluster are capable of completing spermatogenesis: fertilization, normal embryonic development and pregnancy occur when retrieved testicular spermatozoa are used for intracytoplasmic sperm injection. Hum Reprod 1997;12:503-8.

51. Repping S, Skaletsky H, Brown L, et al. Polymorphism for a 1.6-Mb deletion of the human $\mathrm{Y}$ chromosome persists through balance between recurrent mutation and haploid selection. Nat Genet 2003;35:247-51.

52. Lynch M, Cram DS, Reilly A, et al. The Y chromosome $\mathrm{gr} / \mathrm{gr}$ subdeletion is associated with male infertility. Mol Hum Reprod 2005;11:507-12. 
53. Komori S, Kato H, Kobayashi S, et al. Transmission of $\mathrm{Y}$ chromosomal microdeletions from father to son through intracytoplasmic sperm injection. J Hum Genet 2002;47:465-8.

54. Patsalis PC, Sismani C, Quintana-Murci L, et al. Effects of transmission of $\mathrm{Y}$ chromosome AZFc deletions. Lancet (London, England) 2002;360:1222-4.

55. Pryor JL, Kent-First M, Muallem A, et al. Microdeletions in the $\mathrm{Y}$ chromosome of infertile men. $\mathrm{N}$ Engl J Med 1997;336:534-9.

56. Saut N, Terriou $P$, Navarro A, et al. The human $Y$ chromosome genes BPY2, CDY1 and DAZ are not essential for sustained fertility. Mol Hum Reprod 2000;6:789-93.

57. Stuppia L, Calabrese G, Franchi PG, et al. Widening of a Y-chromosome interval-6 deletion transmitted from a father to his infertile son accounts for an oligozoospermia critical region distal to the RBM1 and DAZ genes. Am J Hum Genet 1996;59:1393-5.

58. Lee SH, Ahn SY, Lee KW, et al. Intracytoplasmic sperm injection may lead to vertical transmission, expansion, and de novo occurrence of Y-chromosome microdeletions in male fetuses. Fertil Steril 2006;85:1512-5.

59. Kent-First MG, Kol S, Muallem A, et al. The incidence and possible relevance of Y-linked microdeletions in babies born after intracytoplasmic sperm injection and their infertile fathers. Mol Hum Reprod 1996;2:943-50.

60. Buch B, Galan JJ, Lara M, et al. Absence of de novo Y-chromosome microdeletions in male children conceived through intracytoplasmic sperm injection. Fertil Steril 2004;82:1679-80.

61. Cram DS, Ma K, Bhasin S, et al. Y chromosome analysis of infertile men and their sons conceived through intracytoplasmic sperm injection: vertical transmission of deletions and rarity of de novo deletions. Fertil Steril 2000;74:909-15.

62. Katagiri Y, Neri QV, Takeuchi T, et al. Y chromosome assessment and its implications for the development of ICSI children. Reprod Biomed Online 2004;8:307-18.

63. Siffroi JP, Le Bourhis C, Krausz C, et al. Sex chromosome mosaicism in males carrying $\mathrm{Y}$ chromosome long arm deletions. Hum Reprod 2000;15:2559-62.

64. Papadimas J, Goulis DG, Giannouli C, et al. Ambiguous genitalia, 45,X/46,XY mosaic karyotype, and $\mathrm{Y}$ chromosome microdeletions in a 17 -year-old man. Fertil
Steril 2001;76:1261-3.

65. Alvarez-Nava F, Puerta H, Soto M, et al. High incidence of Y-chromosome microdeletions in gonadal tissues from patients with 45,X/46,XY gonadal dysgenesis. Fertil Steril 2008;89:458-60.

66. Patrat C, Bienvenu T, Janny L, et al. Clinical data and parenthood of 63 infertile and Y-microdeleted men. Fertil Steril 2010;93:822-32.

67. Ferlin A, Speltra E, Garolla A, et al. Y chromosome haplogroups and susceptibility to testicular cancer. Mol Hum Reprod 2007;13:615-9.

68. Stirrat GM. Recurrent miscarriage I: definition and epidemiology. Lancet 1990;336:673-5.

69. Li TC, Makris M, Tomsu M, et al. Recurrent miscarriage: aetiology, management and prognosis. Hum Reprod Update 2002;8:463-81.

70. Dewan S, Puscheck EE, Coulam CB, et al. Y-chromosome microdeletions and recurrent pregnancy loss. Fertil Steril 2006;85:441-5.

71. Karaer A, Karaer K, Ozaksit G, et al. Y chromosome azoospermia factor region microdeletions and recurrent pregnancy loss. Am J Obstet Gynecol 2008;199:662.e1-5.

72. Bellver J, Meseguer M, Muriel L, et al. Y chromosome microdeletions, sperm DNA fragmentation and sperm oxidative stress as causes of recurrent spontaneous abortion of unknown etiology. Hum Reprod 2010;25:1713-21.

73. Venkatesh S, Thilagavathi J, Kumar K, et al. Cytogenetic, $\mathrm{Y}$ chromosome microdeletion, sperm chromatin and oxidative stress analysis in male partners of couples experiencing recurrent spontaneous abortions. Arch Gynecol Obstet 2011;284:1577-84.

74. Li D, Zhang H, Wang R, et al. Chromosomal abnormalities in men with pregestational and gestational infertility in northeast China. J Assist Reprod Genet 2012;29:829-36.

75. Ghorbian S, Saliminejad K, Sadeghi MR, et al. The association between $\mathrm{Y}$ chromosome microdeletion and recurrent pregnancy loss. Iran Red Crescent Med J 2012;14:358-62.

76. Piña-Aguilar RE, Martínez-Garza SG, Kohls G, et al. $\mathrm{Y}$ chromosome microdeletions in Mexican males of couples with idiopathic recurrent pregnancy loss. J Obstet Gynaecol Res 2012;38:912-7.

77. Soleimanian S, Kalantar SM, Sheikhha MH, et al. Association between Y-chromosome AZFc region micro- 
deletions with recurrent miscarriage. Iran J Reprod Med 2013;11:431-4.

78. Pereza N, Crnjar K, Buretic-Tomljanovic A, et al. Y chromosome azoospermia factor region microdeletions

Cite this article as: Golin AP, Yuen W, Flannigan R. The effects of Y chromosome microdeletions on in vitro fertilization outcomes, health abnormalities in offspring and recurrent pregnancy loss. Transl Androl Urol 2021;10(3):1457-1466. doi: 10.21037/tau-19-672 are not associated with idiopathic recurrent spontaneous abortion in a Slovenian population: association study and literature review. Fertil Steril 2013;99:1663-7. 